\title{
ANTIDotE: anti-tick vaccines to prevent tick-borne diseases in Europe
}

\author{
Hein Sprong ${ }^{1 *}$, Jos Trentelman², Ingar Seemann², Libor Grubhoffer ${ }^{3}$, Ryan OM Rego ${ }^{3}$, Ondřej Hajdušek ${ }^{3}$, \\ Petr Kopáček ${ }^{3}$, Radek Šíma ${ }^{3}$, Ard M Nijhof ${ }^{4}$, Juan Anguita ${ }^{5}$, Peter Winter ${ }^{6}$, Bjorn Rotter ${ }^{6}$, Sabina Havlíková7, \\ Boris Klempa ${ }^{7}$, Theo P Schetters ${ }^{8}$ and Joppe WR Hovius ${ }^{2^{*}}$
}

\begin{abstract}
Ixodes ricinus transmits bacterial, protozoal and viral pathogens, causing disease and forming an increasing health concern in Europe. ANTIDotE is an European Commission funded consortium of seven institutes, which aims to identify and characterize tick proteins involved in feeding and pathogen transmission. The knowledge gained will be used to develop and evaluate anti-tick vaccines that may prevent multiple human tick-borne diseases. Strategies encompassing anti-tick vaccines to prevent transmission of pathogens to humans, animals or wildlife will be developed with relevant stakeholders with the ultimate aim of reducing the incidence of tick-borne diseases in humans.
\end{abstract}

Keywords: Ixodes ricinus, Vaccine, Lyme borreliosis, Tick-borne encephalitis, Babesiosis, Public health

\section{Background}

Tick-borne diseases as a public health concern in Europe Ixodes ricinus is a hard tick that transmits a variety of pathogens of medical and veterinary importance. These include Borrelia burgdorferi sensu lato, Borrelia miyamotoi, Anaplasma phagocytophilum, Rickettsia spp., Babesia spp., and tick-borne encephalitis virus (TBEV). The most prevalent tick-borne infection of humans in Europe is Lyme borreliosis, with at least 65,000 documented cases yearly [1]. The most pathogenic infection is caused by TBEV, with 1 to $2 \%$ of patients reportedly dying from the European subtype [2], and with up to $46 \%$ of TBE patients suffering from long-term sequelae [3]. Infection of most other tick-borne pathogens associated with $I$. ricinus, such as Babesia spp., but also B. miyamotoi, is usually mild and may easily go undiagnosed. However, infection of immunocompromised individuals can lead to a progressive and more severe illness [4,5]. A relatively low number of severe human babesiosis cases have

\footnotetext{
*Correspondence: hein.sprong@rivm.nl; j.w.hovius@amc.uva.nl

${ }^{1}$ The National Institute of Public Health and the Environment (RIVM),

Bilthoven, The Netherlands

${ }^{2}$ Academic Medical Center, University of Amsterdam, Center for Experimental and Molecular Medicine, Amsterdam, The Netherlands

Full list of author information is available at the end of the article
}

been reported in literature, which is surprising considering the widespread distribution of Babesia-infected ticks and the size of the population at risk [6].

The incidences of Lyme borreliosis and tick-borne encephalitis are on the rise in several European countries $[1,2,7]$ and diseases caused by other pathogens, such as Neoehrlichia mikurensis, and B. miyamotoi are clearly emerging [5,8]. Environmental (e.g. climate change and landscape management), socio-economic and demographic factors (e.g. population aging and life-styles) synergistically increase the risk of acquiring tick-borne diseases [9-13]. Based on these findings, the European Center for Disease Prevention and Control has predicted that the incidence of tick-borne diseases will rise in the near future [14]. Therefore, the old adage 'prevention is better than cure' also holds true for tickborne diseases.

\section{Current control measures}

Conventional control measures on tick-borne zoonoses, such as the widespread application of detrimental acaricides to control ticks and the culling of wildlife reservoirs, are becoming more and more socially unacceptable [15]. Where the risk of infection is high, and/or the resulting disease severe, vaccines may be the most efficient and costeffective means of prevention and control [16]. Anti-tick 
vaccines targeting other tick species already exist and are being used in the veterinary field. The strategy behind these vaccines is to locally control Rhipicephalus (Boophilus) tick species, and act as a safe and environmentally friendly alternative to acaricides $[17,18]$. Application of anti-tick vaccines was shown to dramatically decrease the incidence of bovine babesiosis [19]. Whether anti-tick vaccines can also be used to (locally) eradicate I. ricinus, and prevent human tick-borne diseases remains to be established. It may not prove to be a easy challenge due to the very large host range of $I$. ricinus and its ability to survive in a variety of habitats, including deciduous and coniferous woodlands, heathlands, moorlands, rough pastures, forests, urban parks, and even gardens [20].

Vaccines against TBEV are available, but require multiple doses and frequent boosters to induce and maintain immunity [21] and the vaccination coverage in many Central and Eastern Europe is remarkably low [22]. A vaccine protecting against Lyme borreliosis is unavailable, but a refined vaccine has recently been tested in a Phase I/II trial [23]. Based on the experiences with the previous Lyme vaccine that was on the American market from 1998 to 2002, it remains to be seen whether a Lyme vaccine will be widely used [24]. There is no human vaccine to prevent babesiosis or any other of the other above-mentioned pathogens. Ideally, one would like to have a single vaccine (for humans), protecting against multiple tick-borne diseases.

\section{The idea behind ANTIDotE}

Rather than developing vaccines against all the pathogens transmitted by $I$. ricinus, one vaccine targeting the tick itself could have the same effect by blocking the transmission of any pathogen. The idea of such a vaccine is supported by the observation that multiple exposures of certain mammalian species to tick bites results in an inability of ticks to successfully take a blood meal, a phenomenon designated as 'tick immunity' [25,26]. Ixodes ticks not only introduce pathogens, but also salivary proteins into the host skin that facilitate their feeding and even the transmission of pathogens by modulating host defense mechanisms. Anti-tick immune responses are based on both cellular and humoral immune responses directed against selected tick (salivary gland) antigens. Of paramount importance, 'tick immunity' impairs tick feeding, but also protects animals from the development of experimental infections with tick-borne pathogens [27-29]. These anti-tick immune responses can be simulated by vaccination of laboratory animals with tick salivary gland extract or selected tick salivary gland proteins [30]. In addition, targeting tick salivary proteins that facilitate the transmission of pathogens from the tick to the host by (neutralizing) antibodies may also prevent successful pathogen transmission, without affecting the tick's ability to feed [31-33]. Notably, humans with hypersensitivity to tick-bites are also at a lower risk of contracting Lyme borreliosis [34]. In other words, the identification

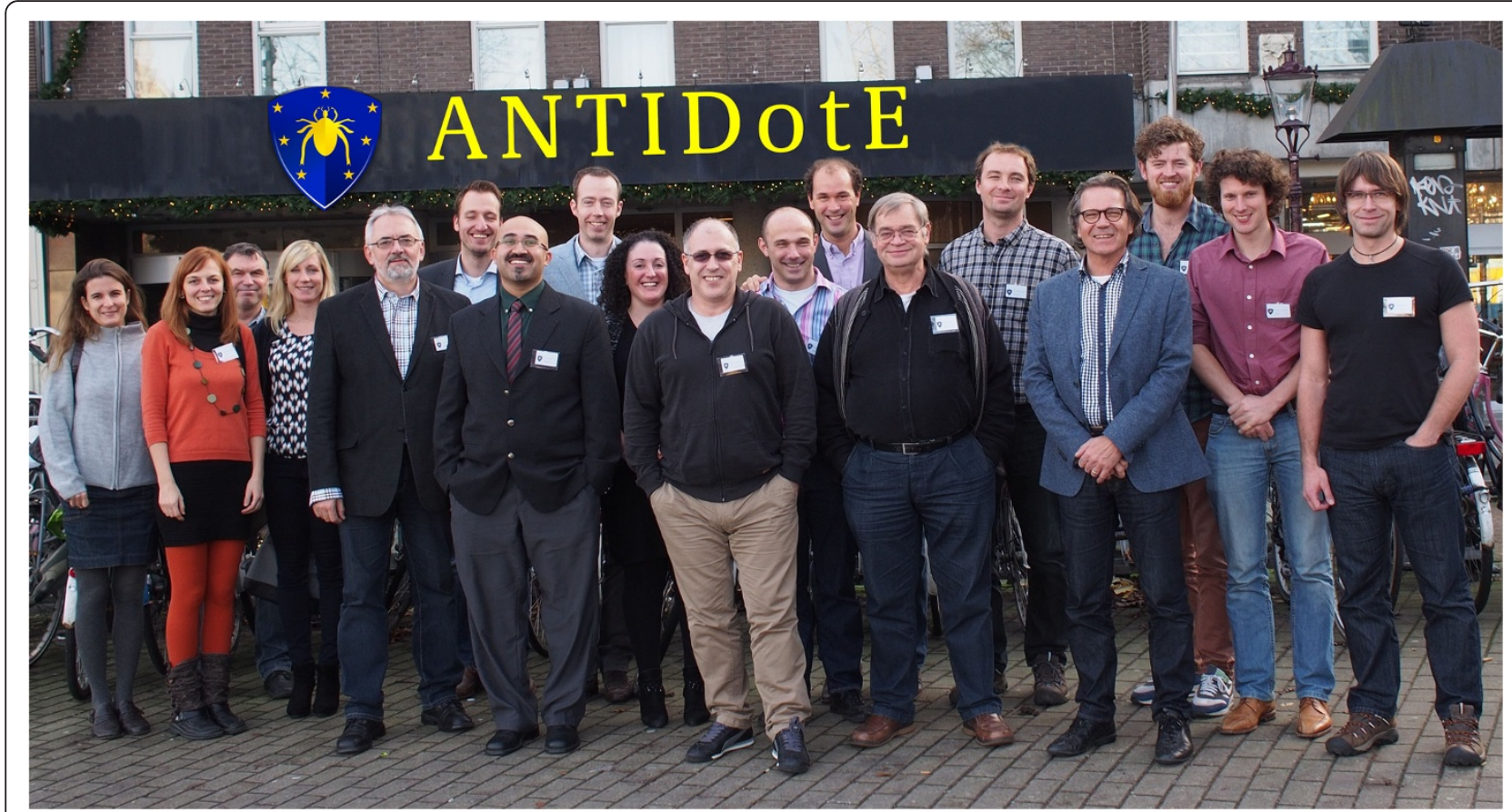

Figure 1 The participants of the official launch meeting of ANTIDotE. This meeting was held in Amsterdam, The Netherlands, in December 2013. 

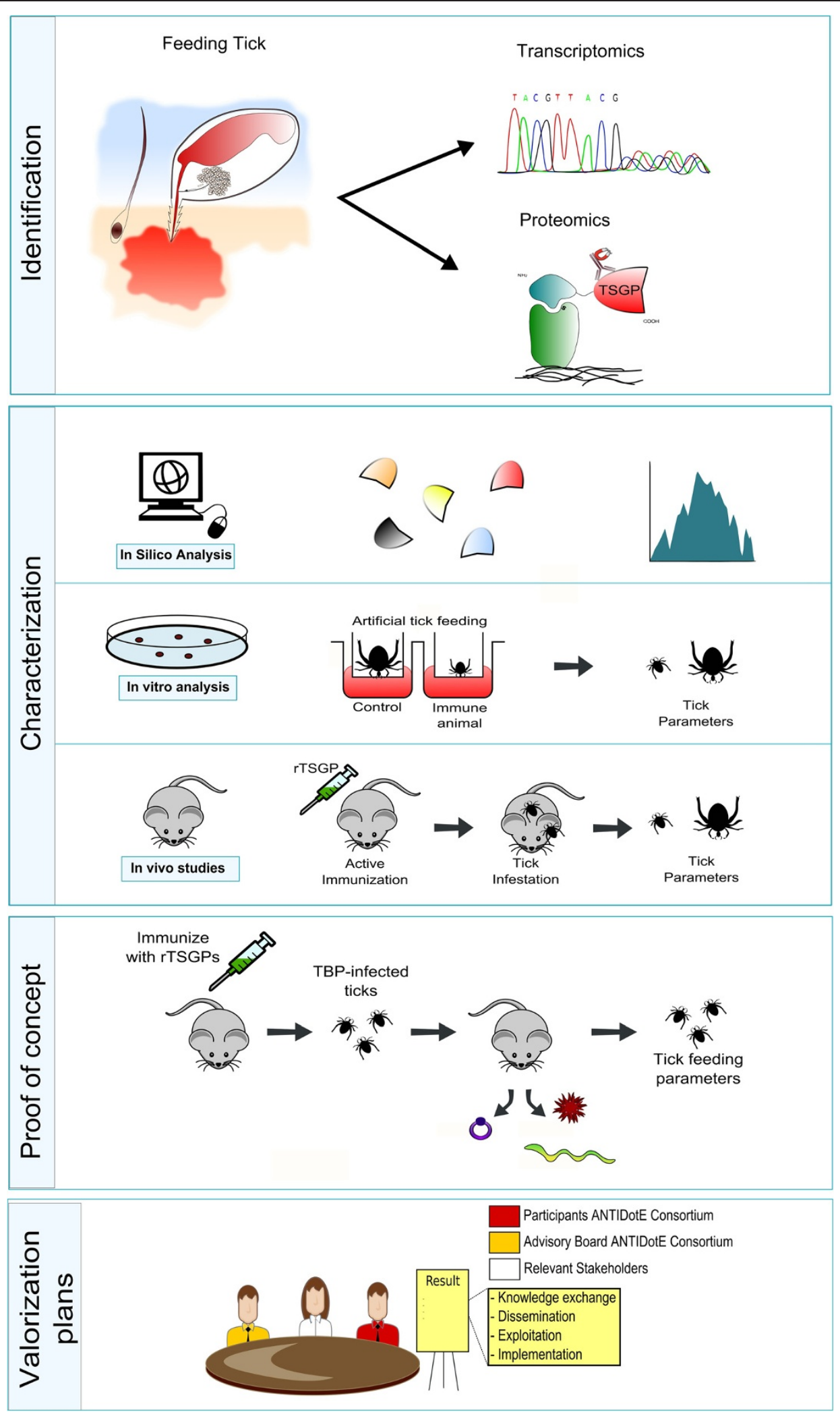

Figure $\mathbf{2}$ (See legend on next page.) 
(See figure on previous page.)

Figure 2 The ANTIDotE approach. Identification: Using state of the art proteomic and transcriptomic approaches we will identify novel tick salivary gland proteins. Characterization: These novel tick salivary gland proteins will be characterized using in silico, in vitro and in vivo techniques. Proof of concept: Promising candidates will be assessed in a proof of concept study as anti-tick vaccines to protect against tick-borne diseases. Both transmission as well as tick feeding parameters will be assessed. The symbols (from left to right) represent Babesia, Borrelia nd TBEV, respectively. Valorization plans: Through an integrated and multidisciplinary approach involving European public health institutes, health organizations and industrial companies, we will examine how to develop anti-tick vaccines and implement these in public health systems in Europe.

and characterization of tick salivary gland proteins involved in feeding and transmission of bacteria, viruses and protozoa will greatly facilitate the development of an antitick vaccine that could prevent multiple human tick-borne diseases. Such a vaccine could either be used in humans directly, or in animals and wildlife in order to indirectly reduce the risk of contracting tick-borne disease for humans.

\section{The ANTIDotE consortium and project The ANTIDotE consortium}

ANTIDotE is the acronym of the project "Anti-tick Vaccines to Prevent Tick-borne Diseases in Europe. It is also the name of the consortium that will push forward the project. The consortium consists of seven European institutes funded by the European Commission through the Seventh Framework Program for Research (FP7Health). The consortium is headed by Dr. Joppe Hovius, Principal Investigator at the Academic Medical Center in Amsterdam, and further consists of scientists from the Institute of Parasitology at the Biology Centre of the Academy of Sciences of the Czech Republic, the Institute for Parasitology and Tropical Veterinary Medicine of the Freie Universität Berlin, Center for Cooperative research in Biosciences from Spain, the medium-sized enterprise GenXPro from Germany, the Institute of Virology of the Slovak Academy of Sciences, and Dutch National Institute for Public Health and Environment. It brings together a unique combination of industrial, research and public health institutes with ample research experience on ticks, anti-tick immune responses, transmission of tick-borne pathogens, anti-tick vaccines and surveillance and control of vector-borne diseases. The official launch meeting was held on December 1st, 2013 in Amsterdam (Figure 1).

\section{The ANTIDotE project}

ANTIDotE's key objective is to identify antigens from $I$. ricinus that could serve as candidates for an anti-tick vaccine, which is able to protect against multiple European tick-borne diseases (Figure 2). Using state of the art proteomic and transcriptomic approaches we will identify and characterize novel tick salivary gland proteins, which will be subsequently assessed as anti-tick vaccines to protect against Lyme borreliosis, TBE and babesiosis in animal models. Importantly, this is not where ANTIDotE stops. We will also explore ways to expedite and facilitate future utilization and implementation of anti-tick vaccines in public health systems [35]. Novel anti-tick vaccines could be used in humans and finding a candidate that holds that potential and protects against multiple human tick-borne diseases is ANTIDotE's main ambition. However, as an alternative approach, anti-tick vaccines that interfere with tick feeding and/or pathogen transmission could also be adapted for use in domesticated animals or wildlife. This could (locally) decrease tick or pathogen populations in the environment, which reduces the risk of contracting tick-borne diseases for humans. The application of vaccines in domesticated animals or wildlife to prevent human disease is a challenge and there are only a few practically implemented precedents [16]. Therefore, through a multidisciplinary and integrated approach with several European public health institutes, in collaboration with relevant stakeholders, such as the European health organizations and end users, the ANTIDotE consortium will examine if and how anti-tick vaccines can be incorporated in health systems in Europe. We will do so by organizing two workshops during the five-year course of the project, at which the different stakeholders (e.g. scientists, clinicians, public health experts, and interested industrial partners) will be invited. For more information we would like to refer to the website www.antidote-fp7.org and interested institutes or individuals are encouraged to contact the leader of the specific work package, Dr. Hein Sprong, or the ANTIDotE coordinator, Dr. Joppe WR Hovius.

\section{Abbreviations}

(r)TSGP: (recombinant) Tick salivary gland protein; TBP: Tick-borne pathogen.

\section{Competing interests}

The authors declare that they have no competing interests.

\section{Authors' contributions}

All authors contributed to the manuscript and approved with the final version.

\section{Acknowledgement}

The research that will lead to these results has received funding from the European Community's Seventh Framework Program under grant agreement 602272-2 (Project ANTIDotE).

\section{Author details}

${ }^{1}$ The National Institute of Public Health and the Environment (RIVM), Bilthoven, The Netherlands. ${ }^{2}$ Academic Medical Center, University of Amsterdam, Center for Experimental and Molecular Medicine, Amsterdam, The Netherlands. ${ }^{3}$ Biology Centre of the Academy of Sciences of the Czech 
Republic (BC ASCR), České Budějovice, Czech Republic. ${ }^{4}$ Institute for Parasitology and Tropical Veterinary Medicine, Freie Universität Berlin (FUB), Berlin, Germany. ${ }^{5}$ Center for Cooperative Research in Biosciences (CIC bioGUNE), Derio, Spain and Ikerbasque Foundation, Bilbao, Spain. ${ }^{6} \mathrm{GenXPro}$ GmbH (GenXPro), Frankfurt am Main, Germany. ${ }^{7}$ Institute of Virology, Slovak Academy of Sciences (IV SAS), Bratislava, Slovak Republic. ${ }^{8}$ Merck Sharp \& Dohme Animal Health, Boxmeer, The Netherlands.

Received: 7 February 2014 Accepted: 19 February 2014 Published: 21 February 2014

\section{References}

1. Rizzoli A, Hauffe H, Carpi G, Vourc HG, Neteler M, Rosa R: Lyme borreliosis in Europe. Euro Surveill 2011, 16(27). Available online: http://www. eurosurveillance.org/NiewArticle.aspx? Articleld=19906

2. Jaenson TG, Hjertqvist M, Bergstrom T, Lundkvist A: Why is tick-borne encephalitis increasing? A review of the key factors causing the increasing incidence of human TBE in Sweden. Parasite Vectors 2012, 5:184

3. Haglund M, Gunther G: Tick-borne encephalitis-pathogenesis, clinical course and long-term follow-up. Vaccine 2003, 21(Suppl 1):S11-S18.

4. Heyman P, Cochez C, Hofhuis A, van der Giessen J, Sprong H, Porter SR, Losson B, Saegerman C, Donoso-Mantke O, Niedrig M, Papa A: A clear and present danger: tick-borne diseases in Europe. Expert Rev Anti Infect Ther 2010, 8:33-50

5. Hovius JW, de Wever B, Sohne M, Brouwer MC, Coumou J, Wagemakers A, Oei A, Knol H, Narasimhan S, Hodiamont CJ, Jahfari S, Pals ST, Horlings HM Fikrig E, Sprong H, van Oers MH: A case of meningoencephalitis by the relapsing fever spirochaete Borrelia miyamotoi in Europe. Lancet 2013, 382:658.

6. Martinot M, Zadeh MM, De Briel D: Human babesiosis. N Engl J Med 2012, 367:1070. author reply 1071-1072.

7. Sumilo D, Bormane A, Vasilenko V, Golovljova I, Asokliene L, Zygutiene M, Randolph S: Upsurge of tick-borne encephalitis in the Baltic States at the time of political transition, independent of changes in public health practices. Clin Microbiol Infect 2009, 15:75-80.

8. Jahfari S, Fonville M, Hengeveld P, Reusken C, Scholte EJ, Takken W, Heyman P, Medlock J, Heylen D, Kleve J, Sprong H: Prevalence of Neoehrlichia mikurensis in ticks and rodents from North-west Europe. Parasite Vectors 2012, 5:74.

9. Medlock JM, Hansford KM, Bormane A, Derdakova M, Estrada-Pena A, George JC, Golovljova I, Jaenson TG, Jensen JK, Jensen PM, Kazimirova M, Oteo JA, Papa A, Pfister K, Plantard O, Randolph SE, Rizzoli A, Santos-Silva MM, Sprong H, Vial L, Hendrickx G, Zeller H, Van Bortel W: Driving forces for changes in geographical distribution of Ixodes ricinus ticks in Europe. Parasite Vectors 2013, 6:1

10. Sprong H, Hofhuis A, Gassner F, Takken W, Jacobs F, van Vliet AJ, van Ballegooijen M, van der Giessen J, Takumi K: Circumstantial evidence for an increase in the total number and activity of Borrelia-infected Ixodes ricinus in the Netherlands. Parasite Vectors 2012, 5:294.

11. Stefanoff P, Rosinska M, Samuels S, White DJ, Morse DL, Randolph SE: A national case-control study identifies human socio-economic status and activities as risk factors for tick-borne encephalitis in Poland. PLoS One 2012, 7:e45511.

12. Godfrey ER, Randolph SE: Economic downturn results in tick-borne disease upsurge. Parasite Vectors 2011, 4:35.

13. Kunze U, TBE I: Tick-borne encephalitis: the impact of epidemiology, changing lifestyle, and environmental factors. Conference report of the 12th Annual Meeting of the International Scientific Working Group on Tick-Borne Encephalitis (ISW-TBE). Vaccine 2011, 29:1355-1356.

14. Lindgren E, Andersson Y, Suk JE, Sudre B, Semenza JC: Public health. Monitoring EU emerging infectious disease risk due to climate change. Science 2012, 336:418-419.

15. Piesman J, Eisen L: Prevention of tick-borne diseases. Annu Rev Entomol 2008, 53:323-343.

16. Monath TP: Vaccines against diseases transmitted from animals to humans: a one health paradigm. Vaccine 2013, 31:5321-5338.

17. de la Fuente J, Almazan C, Canales M, de la Lastra JM P, Kocan KM, Willadsen P: A ten-year review of commercial vaccine performance for control of tick infestations on cattle. Anim Health Res Rev 2007, 8:23-28.

18. Torina A, Moreno-Cid JA, Blanda V, de Mera IG F, de la Lastra JM, Scimeca S, Blanda M, Scariano ME, Brigano S, Disclafani R, Piazza A, Vicente J,
Gortazar C, Caracappa S, Lelli RC, de la Fuente J: Control of tick infestations and pathogen prevalence in cattle and sheep farms vaccinated with the recombinant Subolesin-major surface protein 1a chimeric antigen. Parasite Vectors 2014, 7:10.

19. Valle MR, Mendez L, Valdez M, Redondo M, Espinosa CM, Vargas M, Cruz RL, Barrios HP, Seoane G, Ramirez ES, Boue O, Vigil JL, Machado H, Nordelo CB, Pineiro MJ: Integrated control of Boophilus microplus ticks in Cuba based on vaccination with the anti-tick vaccine Gavac. Exp Appl Acarol 2004, 34:375-382

20. Mulder S, van Vliet AJ, Bron WA, Gassner F, Takken W: High risk of tick bites in dutch gardens. Vector Borne Zoonotic Dis 2013, 13:865-871.

21. Rumyantsev AA, Goncalvez AP, Giel-Moloney M, Catalan J, Liu Y, Gao QS, Almond J, Kleanthous H, Pugachev KV: Single-dose vaccine against tick-borne encephalitis. Proc Natl Acad Sci U S A 2013, 110:13103-13108.

22. Heinz FX, Stiasny K, Holzmann H, Grgic-Vitek M, Kriz B, Essl A, Kundi M: Vaccination and tick-borne encephalitis, central Europe. Emerg Infect Dis 2013, 19:69-76.

23. Wressnigg N, Pollabauer EM, Aichinger G, Portsmouth D, Low-Baselli A, Fritsch S, Livey I, Crowe BA, Schwendinger M, Bruhl P, Pilz A, Dvorak T, Singer J, Firth C, Luft B, Schmitt B, Zeitlinger M, Muller M, Kollaritsch H, Paulke-Korinek M, Esen M, Kremsner PG, Ehrlich HJ, Barrett PN: Safety and immunogenicity of a novel multivalent OspA vaccine against Lyme borreliosis in healthy adults: a double-blind, randomised, dose-escalation phase 1/2 trial. Lancet Infect Dis 2013, 13:680-689.

24. Lantos PM: Lyme disease vaccination: are we ready to try again? Lancet Infect Dis 2013, 13:643-644.

25. Hajdusek O, Sima R, Ayllon N, Jalovecka M, Perner J, de la Fuente J, Kopacek $P$ : Interaction of the tick immune system with transmitted pathogens. Front Cell Infect Microbiol 2013, 3:26.

26. Schuijt TJ, Narasimhan S, Daffre S, DePonte K, Hovius JW, Van't Veer C, van der Poll T, Bakhtiari K, Meijers JC, Boder ET, van Dam AP, Fikrig E: Identification and characterization of Ixodes scapularis antigens that elicit tick immunity using yeast surface display. PloS One 2011, 6:e15926.

27. Hovius JW, van Dam AP, Fikrig E: Tick-host-pathogen interactions in Lyme borreliosis. Trends Parasitol 2007, 23:434-438.

28. de la Fuente J, Kocan KM, Blouin EF: Tick vaccines and the transmission of tick-borne pathogens. Vet Res Commun 2007, 31(Suppl 1):85-90.

29. Labuda M, Trimnell AR, Lickova M, Kazimirova M, Davies GM, Lissina O, Hails RS, Nuttall PA: An antivector vaccine protects against a lethal vector-borne pathogen. PLoS Pathog 2006, 2:e27.

30. Hovius JW, Levi M, Fikrig E: Salivating for knowledge: potential pharmacological agents in tick saliva. PLoS Med 2008, 5:e43.

31. Schuijt TJ, Coumou J, Narasimhan S, Dai J, Deponte K, Wouters D, Brouwer M, Oei A, Roelofs JJ, van Dam AP, van der Poll T, Van't Veer C, Hovius JW, Fikrig E: A tick mannose-binding lectin inhibitor interferes with the vertebrate complement cascade to enhance transmission of the lyme disease agent. Cell Host Microbe 2011, 10:136-146.

32. Dai J, Wang P, Adusumilli S, Booth CJ, Narasimhan S, Anquita J, Fikrig E: Antibodies against a tick protein, Salp15, protect mice from the Lyme disease agent. Cell Host Microbe 2009, 6:482-492.

33. Ramamoorthi N, Narasimhan S, Pal U, Bao F, Yang XF, Fish D, Anguita J, Norgard MV, Kantor FS, Anderson JF, Koski RA, Fikrig E: The Lyme disease agent exploits a tick protein to infect the mammalian host. Nature 2005, 436:573-577.

34. Burke G, Wikel SK, Spielman A, Telford SR, McKay K, Krause PJ, Tick-borne Infection Study G: Hypersensitivity to ticks and Lyme disease risk. Emerg Infect Dis 2005, 11:36-41.

35. Braks M, van der Giessen J, Kretzschmar M, van Pelt W, Scholte EJ, Reusken C, Zeller $\mathrm{H}$, van Bortel W, Sprong H: Towards an integrated approach in surveillance of vector-borne diseases in Europe. Parasite Vectors 2011, 4:192.

doi:10.1186/1756-3305-7-77

Cite this article as: Sprong et al:: ANTIDotE: anti-tick vaccines to prevent tick-borne diseases in Europe. Parasites \& Vectors 2014 7:77. 